In the period considered, the total number of deaths was 11,541 , to which those here given contributed $5,434(47 \%)$. The signs used are of little absolute value apart from the figures; for instance, in October scarlet fever has the sign -, in February and March the sign + , while the figures are 11 and 12 .

In comparing individual months it must be borne in mind that February contains 283 days, the longest months 310 and the others 300 each. So also with the quarters : the third and fourth are equal, 920 days each, while the second has 910 , and the first 903 .

Diphtheria, scarlet fever and typhoid fever are notification diseases. In them the maximum number of deaths fell in the months immediately following those during which the maximum number of cases were reported.

Measles. - Not a notification disease during this period. No death from it in October. Out of 71 deaths, 38, or 53\%, occurred in May and June. In the last four months only tive deaths.

Whooping-Cough. - Not a notification disease. 102 deaths, 47 occurred in third quarter, $46 \%$ of the total. January had a large number, while June and December contained respectively two and three deaths.

Diarrharal Jiseases. - Includes disoases certified under the following names: diarrhœa, summer diarrhœa, infantile diarrhoea, inflammatory diarrhoa, summer complaint, enteritis, gastro-enteritis, entero-colitis, coloenteritis, colitis, cholera infantum. The third quarter contains $84 \%$ of all the deaths from these diseases.

The greatest incidence and largest number of deaths in these diseases probably coincide pretty closely.

Bronchitis and Pneumonia. - Beginning with the third quarter, the minimum one for both, they rise in the second, with a further rise in the fourth, to reach their maximum in the first quarter.

In bronchitis, the rise from the minimum month, August, to the maximum month, January, is an unbroken one, while in the decline April appears to break the regularity.

In pneumonia, the rise from August, the minimum month, to April, the maximum month, has its regularity broken in February and March. In February, we are, of course, dealing with a shorter period than in the other months.

In bronchitis, the fourth plus the first quarter contains $62 \%$ of the total deaths. In pneumonia the same period contains $61 \%$. In bronchitis, the minimum inonth, August, is to the maximum month, January, as 1 is to 3.6. In pneumonia the proportion is as 1 to 4.7 .

Phtlisis. - During the period considered this disease caused $16 \%$ of all the deaths. Its maximum month coincides with the maximum month of pneumonia. While the sigus represent phthisis, pneumonia and bronchitis as above the average during January, February, Murch and April, the figures show the percentage of deaths from those diseases respectively during these three months to have been as follows: bronchitis $45 \%$, pneumonia $46 \%$, phthisis $35 \%$. we take July, August, September and October, it will be seen that bronchitis has fallen to $18 \%$, pueumonia to $17 \%$, while the phthisis deaths are $30 \%$ of the total.

Typhoid F'ever. - In August, September, October and November, 819 cases, $72 \%$ of the total, occurred.

Diphtheria. - Though provailing at all times there is between its maximum and minimum months a difference of more thun $100 \%$. It rises abruptly from Sep- tember to October, and falls abruptly from January to February. From Fubruary to September it seems to oscillate irregularly.

Scarlet Fever. - The proportion of the minimum to the maximum months is as 1 to 3.6. The rise from the minimum to the maximum month is more regular and shorter than the decline, the former comprising four monthly waves, the latter eight. The fourth and first quarters contain $65 \%$ of all the cases.

\section{NOMENCLA'TURE OF PEDICULOSIS. ${ }^{\perp}$}

HY CHALLICS W. ALIEN, M.L., NGW YORK, Surgeon to the C'harily Isospital, etc.

Most of the text-books, in this country at least, divide the subject of pediculosis into the three general varieties: pediculosis capitis, pediculosis corporis and pediculosis pubis.

Against the designation of the first variety I have no objections to offer. 'The pediculus which inhabits the hairy-scalp confines his entire attention to this region and it is only by accident that he is found upon any other portion of the surface. The pediculus which habitually goes by the name of the body-louse or pediculus corporis does not however live upon the body as the head-louse lives upon the scalp. His habitat is in the clothing; and it is only for purposes of feeding, and possibly of exercise and recreation, that he makes excursions upon the skin's surface. If you strip a subject affected with this variety, only a laggard who has been caught unawares can be found upon the skin, and he will make all haste to rejoin those remaining upon the clothing. Instead of laying their eggrs upon the hair-shafts as do both the other varieties, these lice deposit their ova along the seams of the garments. For these reasons, it seems to me, this variety should be called only by its other name, pediculus vestimenti, and the term pediculus corporis be given up exclusively to designate what is now universally known as the pediculus pubis or crab-louse. From the extensive migrations of this last mentioned pest, wandering, as it does, wherever hairs abound, and not even sparing the scalp in rare instances, as in a case of an infant of five months reported by 'Trouessart, ${ }^{2}$ it has come to be variously called according to the situation in which its presence is most prominently made knowu; pediculus inguinalis, pediculus axillarum, pediculus palpebrarum, pediculus ciliorum and pediculus barbce.

Now, all this leads to confusion, and explauations have to be entered into whenever we speak or write of the phtheirius inguinalis as occurring in locations other than the genital regions, and if pediculosis ciliorum or axillarum is mentioned, one must explain, to students at least, that the particular louse in question is the so-called pediculus pubis.

'There is another reason why the latter should be distinguished as the body-louse and that is its decidedly great prevalence in many quarters over the pediculus vestimenti. In my office I see frequent instances of the former in both sexes, and rarely if ever one of the latter. In the report of the Good Samaritan Dispensary for 1891 we find, that, in the two principal classes, 232 phtheiriasis cases were treated. Of these 185 were of the head, 36 were due to the pediculus pubis,

1 Read at the Now York Dermntologloal Socloty, February 23, 1892. - Le Bullotin Medical, January 6, 1802. 
and only 11 to the pediculus vestimenti. Besille this, in the eye cluss, where of necessity only the one kind would be found, there were no less than 85 instances of phtheiriasis ciliorum out of a total of 5,974 eje cases treated. 'The same proportion is found to obtain in former years; thus in 1889 , out of 202 instances of pediculosis, 135 were put down to the credit of the head louse, 56 to that of the pediculus pubis affecting various regions, and again only 11 to the podiculus vestimenti. Ilere, too the proportion is increased by 68 cases of pediculosis of the lids in the eye department.

At the Charity Hospital we naturally have moro phtheiriasis in the skin wards, due to the irritation of the pediculus vestimenti, than to that of the crab-louse; but this is simply because the latter does not, as a rule, cause that amount of scratching and consequent alteration in the skin which would call for hospital treatment. The prevalence of the crab-louse among the patients at largo is, however, very great; and as it is so often found in the armpits, upon the chest, down upon the thighs and legs, in the beard, and upon the margins of the eyolids, it is only due to its enterprise to give it the more dignilied aud comprehensive name, pediculus corporis.

\section{Uliniral gDepartment.}

PANCREATIC CIST APPAREN'LY CUREI) BY INCISION ANI DRAINAGE; RECURRENCE, PERTORATION OF 'THE S'TOMACII, DEA'TH, AUTOPSY.

BY MAURIOIG H. RI(IIARISOS, M.D.

Tine case of D. C. L. was reported in the Boston Medical and Surgical Journal for January 29, 1891. He had been adimitted to the Massachusetts General Hospital on October 10, 1890. A diagnosis of pancreatic cyst was made and operation advised. On October 24, 1890, the cyst was exposed and drained. The tumor, everywhere adherent, was found and drained without any difliculty. He made a good recovery and was discharged from the hospital, wearing a drainage-tube, on the 26 th day of November, 1890 .

February 3,1891 . Mr. L. reported to we that he felt very well indeed, that he had grown stronger and fleshier. He had, from time to time, attacks of dizzi. ness in the head. He still wore the tube. 'There was no change in the character of the clear white fluid discharged from the sinus, and its amount was considerable.

May 26, 1891, he said: "There seoms to be less discharge. There is something about four inches deep which hinders the tube going in. It is just before it strikes tho water." General health and appearance very good.

July 9, 1891. "The discharge has ceased almost entirely, but it is sore in the region of the tube, and there has been, for a week, some matter." I removed the tube and the sinus became closed in a few weeks. During the fall the patient called occasionally and 1 had the opportunity often to examine the abilomen. Nothing abnormal could be detected by physical examination, and I looked upon the case as one of perfect and permanent cure.

On Saturday evening, January 23, 1892, I was

1 Read bofore the Boston Sooloty for Medion Improvomont, Fubruary 8,1802 . asked by 1)r. Cowdrey, of Stoneham, to go out early the following morning prepared to operate upon Mr. L., because it was thought that ho was suffering from acute obstruction of the bowels. I found him in great pain, vomiting constantly large quantities of greenishblack fluid. The abdomen was distended and every. where tymipanitic.

History. - Dr. Cowdrey gave the following history: Some two weeks ayo, Mr. L. was taken with a cold, to which he was subject. With the cold he had quite a severe attack of diarrhoen. The cough which accompanied the cold, and seemed like asthma, left him. 'Then, a week ago Friday', he said that he had been sick all day, and that he could feel a lump in his stomach. That night he was quite restless. Two weeks before that time - that is, between three and four weeks ago - he said that he never felt better in his life, that the old trouble had entirely disappeared. There was nothing in the stomach which he complained of. During the last three or four weeks his appetite has been poor, although otherwise he has been about the same as before. On Saturday he stayed at home all day, and there was no vomiting and no pain. On the Monday previous to my visit he felt no better. Ho referred his trouble to his stomach. On Monday night he took a pill, which produced free operation some time towards morning. 'There was no fever. On 'T'uesday he said that his stomach did not feel right, although he had no pain. Ile could not get rid of that lump in his stomach. He was nervous and restless and has a feeling of distress. On Tuesday night he was taken with the same distress, and we sent him to bed and put on hot flannels. At this time ho began to vomit, which was the first attack of vomiting that he had. I found him, on Wednesday, vomiting what seemed to be bilious matter. 'Temperature was normal, pulso was about 80. I gave him morphia subcutaneously, on account of the distress. I found the epigastrium full, but there was no fulness in the sbdomen. There was this prominence below the ensiform cartilage. There was some nausen and some pain all over him. Tongue was furred. Since my visit nothing has passed him, except some gas this (Sunday) morning. He is terribly thirsty, but he vomits whatever water he drinks immediately.

Physical Examination. - General appearance fair. Tongue coated slightly. There is incessunt vomiting of vory durk, greenisli fluid, almost black, and odorless. Over the scar of the original operation there is a slight bornia. The abdomen is every where tympanitic. Deep pressure reveals a tumor which fills the epigastrium and extends from the region of the liver to that of the spleen. In front of the tumor it is everywhere tympunitic. There is no tenderness.

I could not satisfy myself that there was any fluctuation. His condition was not good. Pulse was 120, and of poor quality ; face flushed, and expression auxious. He said he preferred to die rather than to be obliged to wear a tube all his life. It soemed to we that, on the chances, tho tumos had retilled, and that the obstruction which apparently existed was due to the pressure of the mass upon the duodenum, or the upper intestine somewhere. I advised immediate inter. ference with the hope of finding something which could be relieved by a very short operation.

Assisted by Dr. J. II. Siwasey, of New York, 1 opened the abdomen through the scar of the former operation. On separating the adhesions, I found the 